\title{
Ethylene Fueled Scramjet Combustion Experiments
}

\author{
Deng Weixin ${ }^{1,2}$, Le Jialing ${ }^{2}$, Yang Shunhua ${ }^{2}$, Tian Ye $^{2}$, Zhang Wanzhou ${ }^{1,2} \&$ Xu Mingheng ${ }^{1}$ \\ ${ }^{1}$ School of Mechanical Engineering, Southwest Jiaotong University, Chengdu, Sichuan, China \\ ${ }^{2}$ Science and Technology on Scramjet Laboratory, Hypervelocity Aerodynamics Institute of CARDC, Mianyang, \\ Sichuan, China \\ Correspondence: Deng Weixin, School of Mechanical Engineering, Southwest Jiaotong University, Chengdu, \\ China. Tel: 86-187-8054-0016. E-mail: dengweixin21@yahoo.com.cn
}

Received: March 19, 2013

Accepted: April 9, $2013 \quad$ Online Published: April 19, 2013

doi:10.5539/mas.v7n5p51

URL: http://dx.doi.org/10.5539/mas.v7n5p51

\begin{abstract}
Effect of fueling scheme on ethylene-fueled scramjet combustion performance is investigated based on pulse wind-tunnel direct connected experiment platform. Both numerical computing and optical diagnosing are employed to reveal the physical features of the scramjet model. The structure of combustor flow-field is uncovered by high speed schlieren experiments. Also the structure is product by numerical computing. The good agreement between experiment results and computing results validated the reliability of numerical computing. The first and second injector's lean limits and rich limits for combustion are obtained through injecting characteristics experiments. The time evolution of flame with ethylene injected at different single injector are demonstrated by high speed videos. The flame stabilization mode for the first injector is "fuel injection jet-wake stabilized mode", which for the second injector is "cavity stabilized mode".
\end{abstract}

Keywords: scramjet, fueling scheme, flame structure, lean limit, rich limit, combustion performance

\section{Introduction}

Scramjet (supersonic combustion ramjet) is a competitive device to offer high speed and inexpensive hypersonic air breathing propulsion. Because it uses the oxygen in the atmosphere, the non-effective play-load is dropped remarkably (Heiser \& Pratt, 1994). The scramjet engine which uses no rotating parts will power vehicles hundreds of miles in minutes, make rapid global travel and affordable access to space a reality. There are many research programs to investigate the fundamental hypersonic phenomena and to develop technologies deemed critical to the realization of next generation aerospace vehicles, including X43, X51, Hyshot, HIFiRE et al. (Marshall, 2005; Jackson, 2004; Fureby, 2011; Cabell, 2011).

The main challenge of scramjet propulsion is that the supersonic combustion of hydrocarbon fuel should accomplish in the order of millisecond. Generally speaking, combustion is an exothermic chemical process which requires fuel, oxidizer, initiation energy and time for the chemical reaction to take place. For fuel injecting influence, the effects of fuel and air injection are experimentally studied in a cavity based flame-holder in a supersonic flow (Allen, 2005). It is showed that cavity based fuel injection and flame-holding offer an obstruction-free flow path in hydrocarbon fueled scramjet engines. In the view of igniting difficult, the least input energy needed to ignite hydrocarbon fuels are studied by numerical simulating (Hatakeyama, 2010). It is found that $25 \mathrm{~kW}$ net input energy of the igniter was needed for the ignition of ethylene, which was larger than that for the ignition of hydrogen by 5 times. During supersonic combustion process, a longitudinal mode of thermo-acoustic instability may develop in a spatial domain reaching from the shock train to the flame zone. These characterization would influence fuel entrainment、flame structure and combustion performance (Lin, 2007; Collatz, 2009; Tam, 2009). For flame stabilization, two modes are brought forward, including "fuel injection jet-wake stabilized mode" and "cavity stabilized mode". Different injecting location would experience different stabilization mode (Micka, 2009).

However, these studies almost all only looked at an aspect of the complicated and coupled physical phenomena in scramjet. There are many inexplicit details need to be investigated. Therefore, the objectives of this study are to explore flame structures, combustion characters and operation limits of a newly-deigned scramjet operated at different fueling schemes. Based on pulse wind-tunnel direct connect experiment plat-form in china aerodynamics research and development center (CARDC), effect of ethylene fueling schemes on scramjet 
combustion performance is investigated systematically. Both numerical computing and optical diagnose are employed in this research. The structure of combustor flow-field is uncovered by high speed schlieren experiments. The first and second injector's lean limits and rich limits for combustion are obtained through injecting characteristics experiments. The time evolution of flame with ethylene injected at different single injector are demonstrated by high speed videos. Also the flame stabilization modes for these injectors are realized.

\section{Experimental Method}

\subsection{Test Article}

The experiments are carried out on the pulse wind-tunnel direct connect experiment plat-form at china aerodynamic research and development center (CARDC). The test facility is made up by several subsystems including gas source system, oxygen-rich air supply system, hydrogen supply system, combustion heater, facility nozzle and vacuum tank, as illustrated in Figure 1. Combined with the currently available Mach 2, 2.6 and 3 facility nozzles, the air heater is fine-tuned to simulate discrete flight conditions from Mach 4 to 6.5 (Table 1).

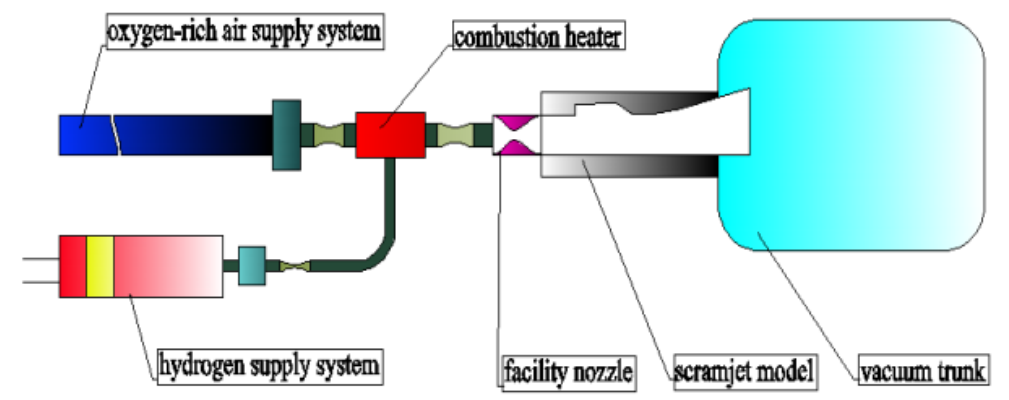

Figure 1. Sketch of pulse wind tunnel

Table 1. Performance parameters of wind tunnel

\begin{tabular}{ccccc}
\hline $\begin{array}{c}\text { Total temperature } \\
/ \mathrm{K}\end{array}$ & $\begin{array}{c}\text { Total pressure } \\
\mathrm{Mpa}\end{array}$ & Mach & $\begin{array}{c}\text { Mass flux } \\
/(\mathrm{kg} / \mathrm{s})\end{array}$ & $\begin{array}{c}\text { Test time } \\
/ \mathrm{ms}\end{array}$ \\
\hline $900 \sim 1700$ & $0.8 \sim 2.7$ & $2 \sim 3$ & $2.6 \sim 3.2$ & 300 \\
\hline
\end{tabular}

\subsection{Diagnostics}

Pressure taps are strategically positioned throughout the entire rig for instrumentation and health monitoring. Based on the value of pressure, three scale transducers with the precision of $0.02 \%$ are used, including $0.3 \mathrm{MPa}$, $0.7 \mathrm{MPa}$ and $15 \mathrm{MPa}$. The data acquisition system consists of an amplifier, a recorder, a controlling compute and a 128-channel electronic pressure scanning system.

\subsection{Scramjet Model}

The scramjet flow-path of the present study consists of a heat-sink rectangular isolator, a rectangular combustor featuring a recessed cavity flame-holder and flush-wall perpendicularity injectors, and a diverging nozzle. The isolator has a rectangular cross-section with a height of $50 \mathrm{~mm}$, a width of $100 \mathrm{~mm}$, and a length of $415 \mathrm{~mm}$. The combustor has a total length of $1285 \mathrm{~mm}$. The recessed cavity flame-holder is located at the divergent top wall. A schematic of this scramjet model is shown in Figure 2. The cavity geometry is fixed with depth $18 \mathrm{~mm}$ and length $196 \mathrm{~mm}$, which make the ratio of length versus depth equal to 11. Six banks of injectors named from "injector I " to "injector VI", three banks each on the top and bottom walls, are designed to provide various fueling options. For the present study, only the "injector I " and "injector II" are activated for fuel delivery. All injectors have the same diameter of $1 \mathrm{~mm}$. Unheated ethylene is used as the main fuel and hydrogen is used as pilot fuel to ignite ethylene. Location for pilot hydrogen injecting is near injector II with $10 \mathrm{~mm}$ spacing in flow direction. The mass flux of hydrogen is only $0.5 \mathrm{~g} / \mathrm{s}$. For the present study, each combustor sidewall is equipped with one $240 \times 160 \mathrm{~mm}$ quartz window for flame visualization. These windows are located around the cavity flame-holder for the observation of successful flame ignition and the establishment of sustained combustion. 


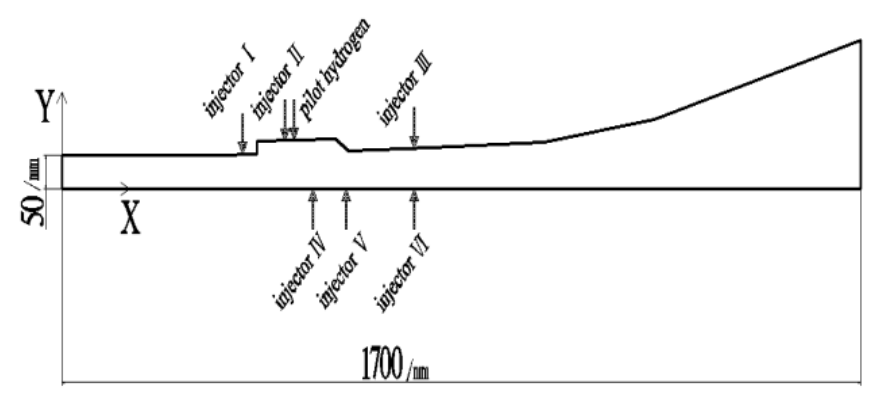

Figure 2. Sketch of scramjet

\subsection{Numerical Approach}

The numerical computing is accomplished using the software "AHL3D" developed by CARDC (Yang, 2005). This code can be used to solve the Reynolds-averaged conservation equations (in 2-D, axisymmetric, or 3-D form) with a cell-center finite volume method, which is appropriate for calorically perfect gas or for an arbitrary mixture of thermally perfect gases undergoing non-equilibrium chemical reactions. The inviscid fluxes can be computed using a 3rd-order MUSCL method with Steger-Warming flux-splitting scheme, AUSM scheme, AUSMPW scheme, or a low-diffusion flux vector splitting scheme. The viscous fluxes are evaluated using the gradients theorem on a shifted control volume. The MUSCL parameter is set equal to $1 / 3$ to minimize truncation error. The solutions are advanced in time with a LU-SGS scheme. A dual-time step sub-iteration scheme is used to compute unsteady flows. More details about the software can be found in the reference (Le, 2011).

\section{Results and Discussion}

In this section, results of both experiments and computing for non-reacting and reacting cases are presented. First, details of flow-field for non-reacting case are discussed. Then the time evolution of flame for ethylene injected at "injector I " and "injector II" respectively are estimated. Finally, the combustion lean limits and rich limits for these two injectors are brought forward. All the inflow conditions for the experiments and computing in this study are listed in the Table 2 .

Table 2. Inflow conditions of experiment

\begin{tabular}{lccc}
\hline Mach & $\begin{array}{c}\text { Total pressure } \\
/ \mathrm{MPa}\end{array}$ & $\begin{array}{c}\text { Total temperature } \\
/ \mathrm{K}\end{array}$ & $\begin{array}{c}\text { Inflow air mass flux } \\
/(\mathrm{kg} / \mathrm{s})\end{array}$ \\
\hline 2.1 & 0.8 & 937 & 3.09 \\
\hline
\end{tabular}

\subsection{Flow-Field for Non-Reacting Case}

All the features of the flow-field without combustion are gained by the numerical computing. The shock wave train of cavity area is exposed in the high speed schlieren experiments. The computed pressure contours in the flow-path are given in Figure 3. A weak expand wave is generated at the lip of cavity as the boundary layer separates from the wall. The reattachment of the shear layer occurs at the aft wall of cavity, which produces a compression wave and makes a high temperature and high pressure region. This region is the main place for combustion which will be proved by the next experiments. So this cavity is an acoustically-open cavity. At the bottom wall, a large scale wall boundary separation appears as a result of shock wave-boundary interactive.

Figure 4 illustrates the results of high speed schlieren experiments. From this figure, the shear layer (1), expand wave (2), reattachment wave (5) and the separation region (4) are all exhibit clearly. Also there are some intrusively wave series arising out of model manufacturing and assembling process, like wave (6) and wave (3). Figure 5 gives the numerical schlieren map of cavity. It can be found that all the physical features of cavity flow can be catch by the numerical computing with a comparison to the experiment result. The wall pressure distribution for non-reacting case got from experiment and computing are illustrated in Figure 6. The trend and absolute values of pressure got from experiment and computing are almost consistent except two spots in the cavity. Again it validates the reliability of computing to expose the physical essential. 


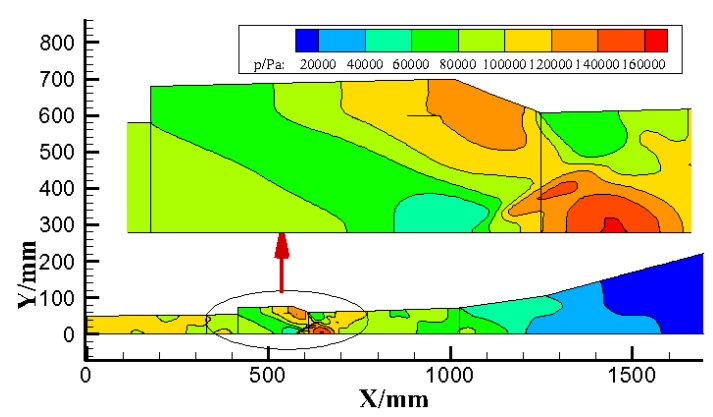

Figure 3. Pressure contours of un-reacting case

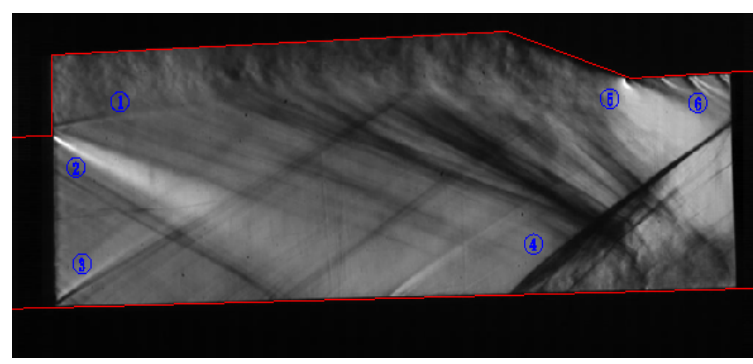

Figure 4. Cavity schlieren map of un-reacting case

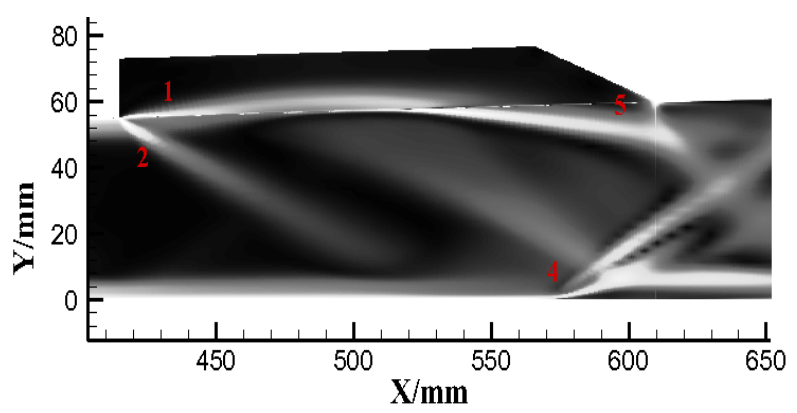

Figure 5. Cavity numerical schlieren map of un-reacting case

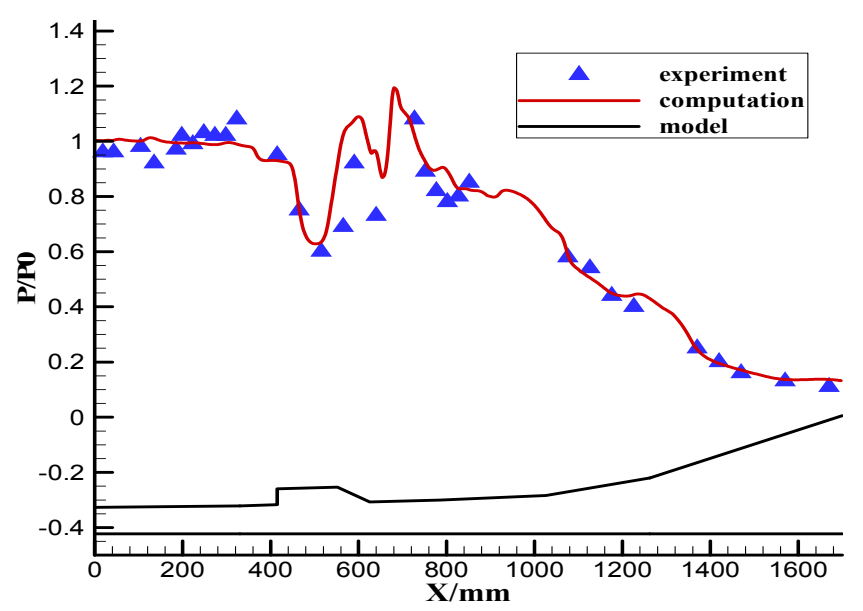

Figure 6. Wall pressure under cold flow condition

\subsection{Results for Ethylene Injected at "Injector I "Solely}

\subsubsection{Time Evolution of Flame}

The "injector I" locates at cavity upstream, see in the Figure 2. The time schedule in Figure 7 is employed as 
test sequence for this experiment. Hydrogen is injected into scramjet model at $\mathrm{t}=195.0 \mathrm{~ms}$ and turned off at $\mathrm{t}=295.0 \mathrm{~ms}$. Ethylene is injected into scramjet model at $\mathrm{t}=215.0 \mathrm{~ms}$ and last to $\mathrm{t}=440.0 \mathrm{~ms}$.

The time evolution of flame is laid out in Figure 8. All the images are got by high speed video. The frame frequency is $5000 \mathrm{f} / \mathrm{s}$. Take the time when the data acquisition system starts working as the time zero point. The pilot hydrogen auto-ignition takes place at $\mathrm{T}=231.8 \mathrm{~ms}$. Then flame propagates upstream and downstream until fills the cavity fully (see in Figure 8 (a)). Ethylene is ignited by the pilot hydrogen flame at T=270.9 ms. The combustion reacting is intensive and the main reaction zone locates at the upper half part of flow-field (see in Figure 8 (b)). The pilot hydrogen is closed $24.1 \mathrm{~ms}$ later after ethylene ignition. Ethylene sustains steady combustion alone until the end of experiment (see in Figure 8 (c)). When ethylene combusts alone, the main reaction zone locates in the shear layer and propagates into cavity and flow-field downstream. In other words, it is not the cavity but the ethylene jet wake that is the main sustaining source for ignition and combustion. The flame-holding mode can be called "fuel injection jet-wake stabilized mode".

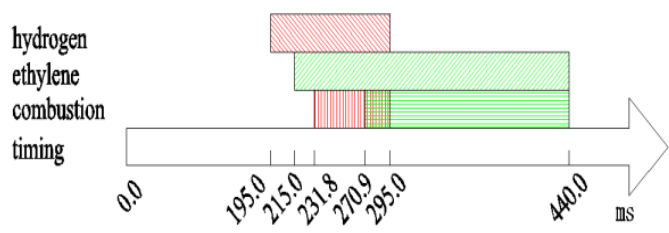

Figure 7. Experiment timing for fuel injected at first injector

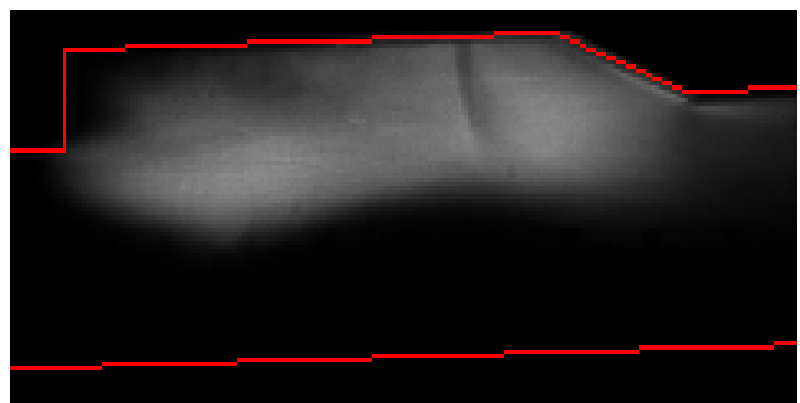

(a) Pilot hydrogen auto-ignition, $\mathrm{t}=231.8 \mathrm{~ms}$

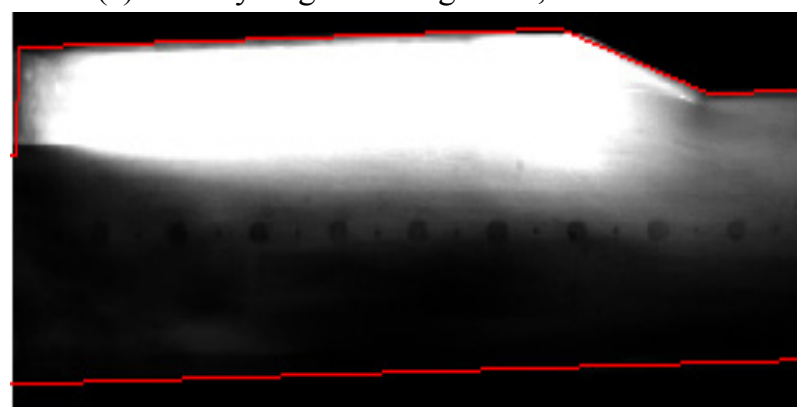

(b) Combustion of hydrogen and ethylene, $\mathrm{t}=284.8 \mathrm{~ms}$

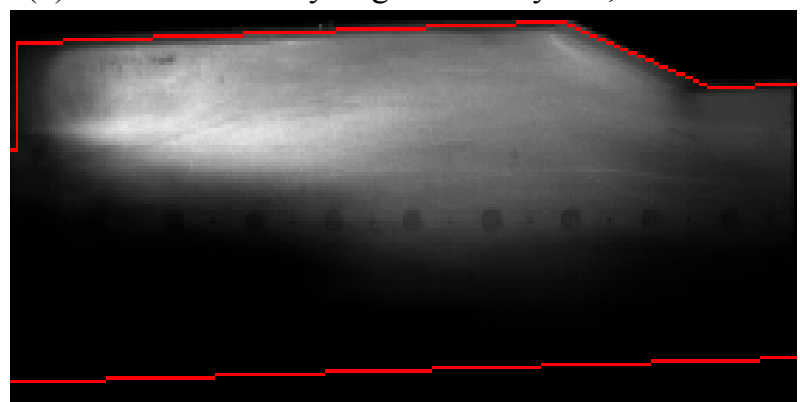

(c) Combustion of ethylene only, $\mathrm{t}=295 \mathrm{~ms}$

Figure 8. Time evolution of flame, fuel injected at first injector 


\subsubsection{Combustion Limits for "Injector I"}

The combustion limits in this paper are defined from the view of combustion performance. The lean limit is the least fuel equivalence ratio (ER) must be injected into the scramjet to produce $10 \%$ pressure raise than cold condition at each measure spot. In the view of actually application, if the combustion pressure is close to the one of non-reacting case, the thrust computed from wall pressure would not be able to offer enough propulsion. The rich limit is the largest fuel equivalence ratio can be injected into scramjet when the isolator can accommodate the shock waves produced by combustion. Obviously, good combustion characteristic means a smaller lean limit and a larger rich limit.

The combustion pressure profiles for various ERs when ethylene injected at "injector I " solely are shown in Figure 9. The least ER used in these experiments is 0.06 , which produces a combustion pressure almost equal to cold wall pressure. The differences at each measuring spot between reacting and non-reacting cases are less than $10 \%$. It is hard to affirm the existence of reacting. When the ER increases to 0.076 , the differences between reacting and non-reacting cases become larger than $10 \%$. So the lean limit for "injector I " is fixed as 0.076 . The largest ER used in these experiments is 0.327 , which gets the combustion produced shock waves propagating upwind till to the entry of isolator. If a larger ER is used, the isolator could not accommodate the shock waves any more. This would cause the scramjet inlet un-start and should be avoided. According to the definition above, the rich limit is 0.327 for "injector I ".

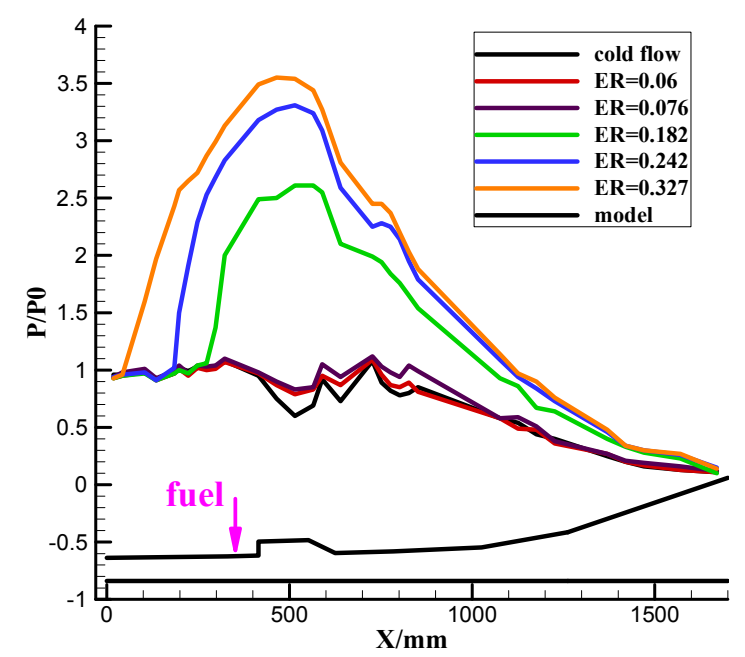

Figure 9. Wall pressures with variable ER, fuel injected at first injector

\subsection{Results for Ethylene Injected at "Injector II"Solely}

\subsubsection{Time Evolution of Flame}

Be similar to the "injector I" tests, the test sequence for "injector II" presents in Figure 10. The time evolution of flame is illustrated in Figure 11. All the images are got by high speed video. The frame frequency is still $5000 \mathrm{f} / \mathrm{s}$. Take the time when the data acquisition system starts working as the time zero point. The pilot hydrogen auto-ignition takes place at $\mathrm{T}=232.2 \mathrm{~ms}$. The time for hydrogen auto-ignition is almost the same compared to "injector I " tests (see in Figure 11 (a)). Ethylene is ignited by the pilot hydrogen flame at T=274.9 ms. It needs $4 \mathrm{~ms}$ more to start reacting for ethylene injected at cavity than at cavity upstream (see in Figure 11 (b)). The reason may come from the fact that the re-circulating movement of ethylene in the cavity needs more time to achieve flammable mixing with main stream. The pilot hydrogen is closed at $\mathrm{T}=295 \mathrm{~ms}$. The self-sustained combustion of ethylene continues until the end of experiment (see in Figure 11 (c)). When ethylene combusts alone, the main reaction takes place in the aft wall corner of cavity and a weak combustion occurs in the shear layer. The conclusion can be drawn as the cavity is the main sustaining source for ignition and combustion. The flame-holding mode can be called "cavity stabilized mode". 


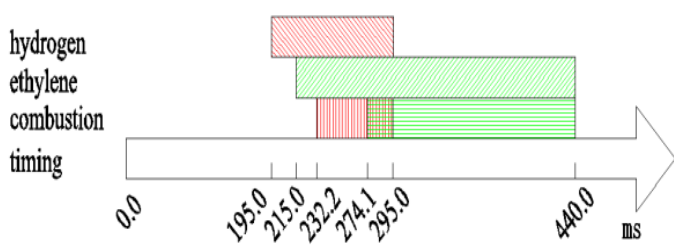

Figure 10. Experiment timing for fuel injected at first injector

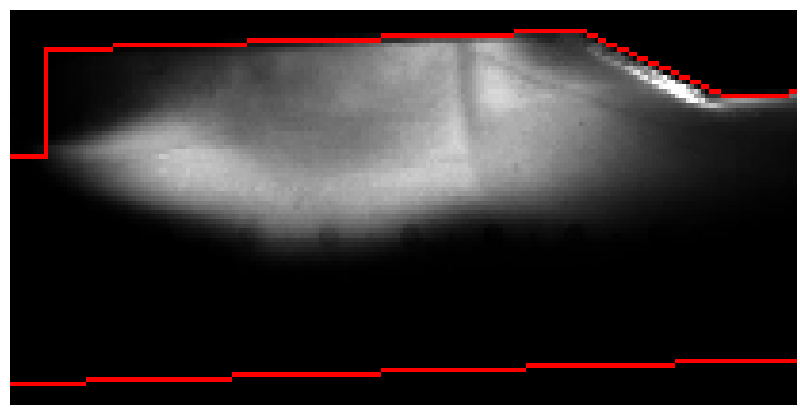

(a) Pilot hydrogen auto-ignition, $\mathrm{t}=232.2 \mathrm{~ms}$

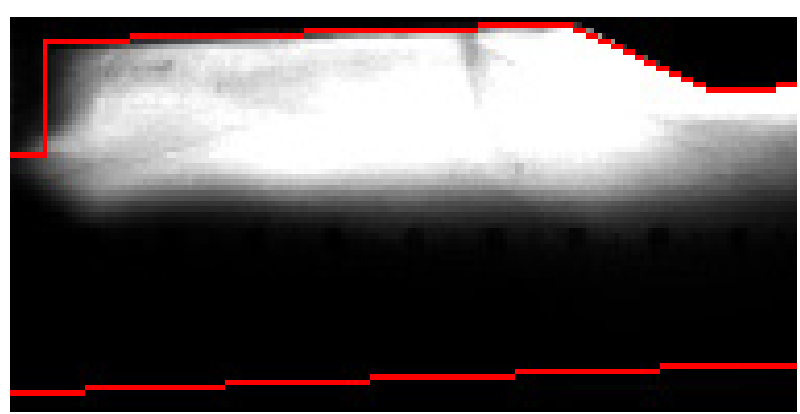

(b) Combustion of hydrogen and ethylene, $\mathrm{t}=274.1 \mathrm{~ms}$

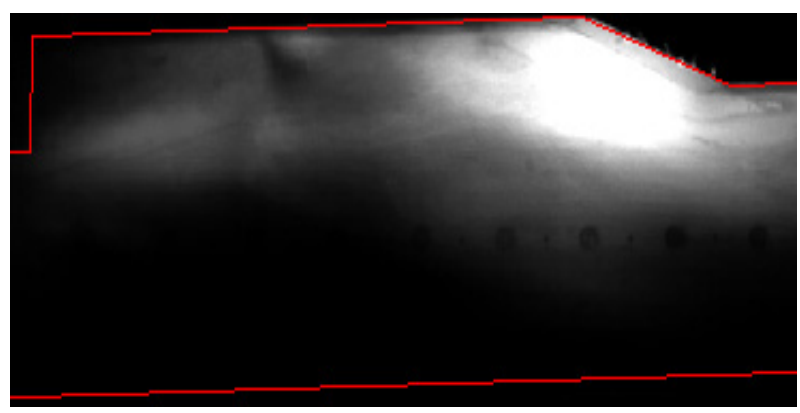

(c) Combustion of ethylene only, $\mathrm{t}=295 \mathrm{~ms}$

Figure 11. Time evolution of flame, fuel injected at second injector

\subsubsection{Combustion Limits for "Injector II"}

The combustion pressure profiles for various ERs when ethylene injected at "injector I" only are shown in Figure 12. The least ER tested in experiment is 0.077 , which makes the combustion pressure equal to the cold one. Increase ER to 0.09 makes a remarkable pressure increasing. A difference larger than $10 \%$ is observed in pressure profiles between acting and non-acting cases. So the lean limit for "injector II" is fixed as 0.09 . The largest ER tested is 0.535 , which makes the combustion shock wave getting out of isolator entry. Decrease the ER to 0.471 makes the pressure falling evidently, especially in the isolator. The pressure climbing point happens to locate at the isolator entry. So ER 0.471 is the rich limit for the "injector II". Note that the rich limit for "injector II" is much larger than the one for "injector I". It can be explained by the location function of 
injectors. Injector in isolator ("injector I ") makes fuel reacting upstream and moves pressure climbing point upwind. So the rich limit is reduced. The step of cavity plays a good role in preventing pressure rise, what offers a larger rich limit.

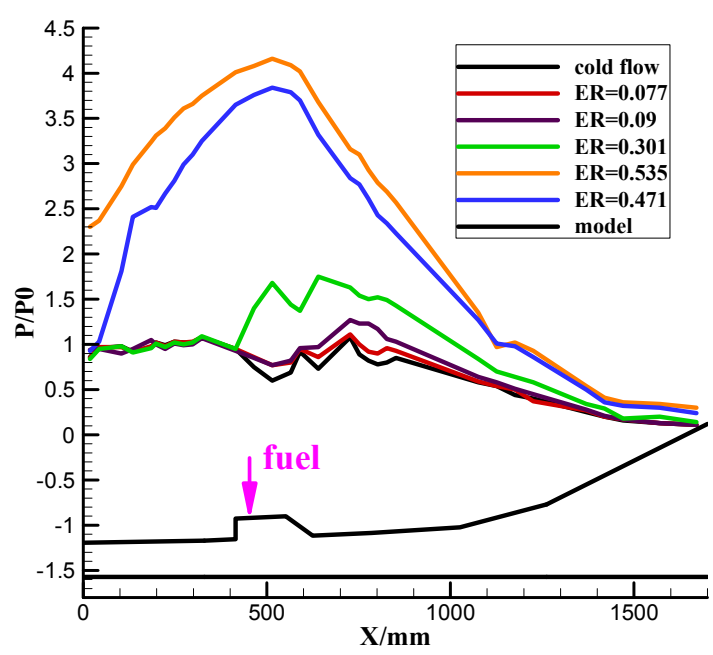

Figure 12. Wall pressures with variable ER, fuel injected at second injector

\section{Summary and Conclusions}

An intensive research is carried out to explore the combustion characteristics of a model scramjet combustor. Both pulse wind tunnel direct connect experiments and numerical computing are employed. The flow-field structure is uncovered by pressure measuring and optical diagnose. Two injectors are used for testing. The time evolution of flame is illustrated by high speed videos. Lean and rich limits for these injectors are gained respectively. The main conclusions are listed as fellow:

(1) The cavity used in this study is an acoustically-open cavity. The schlieren maps got by experiment and computing are coincident. The consistency of pressure values gained by experiment and computing validates the reliability of computing.

(2)Pilot hydrogen flame can ignite ethylene wherever it is injected from. But the ethylene injected in cavity need $4 \mathrm{~ms}$ more to begin combustion than injected at cavity up-stream. The flame holding mode for "injector I " is "fuel injection jet-wake stabilized mode". And the flame holing mode for "injector II"is "cavity stabilized mode".

(3) The lean limit for the two injector are almost the same, 0.076 for "injector I "and 0.09 for "injector II ". But the rich limits are different for the two injectors, 0.327 for "injector I "and 0.471 for "injector II". The main reason for this difference may come from the injecting location function.

\section{References}

Allen, W., King, P., Gruber, M., Carter, C., \& Hsu, K. Y. (2005). Fuel-air injection effects on combustion in cavity-based flameholders in a supersonic flow. 41th AIAA/ASME/SAE/ASEE Joint Propulsion Conference \& Exhibit, July 10-13. 2005. Tucson, Arizona. http://dx.doi.org/10.2514/6.2005-4105

Collatz, M., Gruber, M., Olmstead, D., Branam, R., Lin, K. C., \& Tam, C. J. (2009) Dual cavity scramjet operability and performance study. 45th AIAA/ASME/SAE/ASEE Joint Propulsion Conference \& Exhibit, August 2-5, 2009. Denver, CO.

Fureby, C., Chapuis, M., Fedina, E., \& Karl, S. (2011). CFD analysis of the HyShot II scramjet combustor. Proceedings of the Combustion Institute, 33, 2399-2405. http://dx.doi.org/10.1016/j.proci.2010.07.055

Hass, N., Cabell, K., Storch, A., \& Gruber, M. (2011). HIFiRE direct-connect rig (HDCR) phase I scramjet test results from the NASA Langley arc-heated scramjet test facility. 17th AIAA International Space Planes and Hypersonic Systems and Technologies Conference, April 11-14, 2011. San Francisco, Califomia. http://dx.doi.org/10.2514/6.2011-2248

Hatakeyama, R., Tomioka, S., Izumikawa, M., \& Okuno, Y. (2011). Research on combustion of hydrocarbon huel in a supersonic combustor. 47th AIAA/ASME/SAE/ASEE Joint Propulsion Conference \& Exhibit, July 
31-August 3, 2011.

Heiser, W. H., \& Pratt, D. T. (1994). Hypersonic Airbreathing Propulsion. American institute of aeronautics and astronautics.

Jackson, T. A., Eklund, D. R., \& Fink, A. J. (2004). High speed propulsion: Performance advantage of advanced materials. Journal of Materials Science, 39, 5905-5913. http://dx.doi.org/ 10.1023/B:JMSC.0000041687.37448.06

Le, J. L., Yang, S. H., \& Wang, X. Y. (2011). Numerical Investigations of Unsteady Spray Combustion in a Liquid Kerosene Fueled Scramjet. ISABE 2011-1524.

Lin, K. C., Jackson, K., Behdadnia, R., Jackson, T., Ma, F. H., Li, J., \& Yang, V. (2007). Acoustic characterization of an ethylene-fueled scramjet combustor with a recessed cavity flameholder. 43rd AIAA/ASME/SAE/ASEE Joint Propulsion Conference \& Exhibit, July 8-11, 2007. Cincinnati, OH.

Lin, K. C., Tam, C. J., \& Jackson, K. (2009). Study on the operability of cavity flameholders inside a scramjet combustor. 45th AIAA/ASME/SAE/ASEE Joint Propulsion Conference \& Exhibit, August 2-5, 2009. Denver, CO. http://dx.doi.org/10.2514/6.2009-5028

Marshall, L. A., Bahm, C., \& Corpening, G. P. (2005). Overview with results and lessons learned of the X-43A mach 10 flight. AIAA/CIRA 13th International Space Planes and Hypersonics Systems and Technologies Conference.

Micka, D. J., \& Driscoll, J. F. (2009). Combustion characteristics of a dual-mode scramjet combustor with cavity flameholder. Proceedings of the Combustion Institute, 32, 2397-2404. http://dx.doi.org/10.1016/j.proci.2008.06.192

Yang, S. H., \& Le, J. L. (2005). Computational Analysis of a Kerosene Fueled Scramjet. ISABE 2005-1195. 